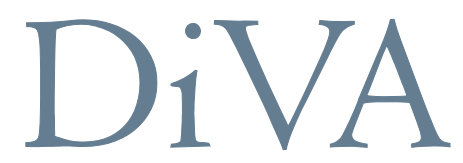

http://uu.diva-portal.org

This is an author produced version of a paper published in Journal of Evolutionary Biology, the journal of the European Society of Evolutionary Biology (ESEB). This paper has been peer-reviewed but does not include the final publisher proof-corrections or journal pagination.

Citation for the published paper:

Abbott, Jessica K.; Svensson, Erik I.

"Phenotypic and genetic variation in emergence and development time of a trimorphic damselfly"

Journal of Evolutionary Biology, 2005, Vol. 18, Issue 6, pp. 1464-1470

http://dx.doi.org/10.1111/i.1420-9101.2005.01019.x

The definitive version is available at www.blackwell-synergy.com. Access to the definitive version may require subscription. 


\section{Phenotypic and genetic variation in emergence and development time of a trimorphic damselfly}

J. Abbott* and E. I. Svensson

Department of Animal Ecology

Ecology Building

Lund University

SE-223 63 Lund, Sweden

*Author for correspondence: Jessica.Abbott@zooekol.lu.se

Phone: +4646 2223701

Fax: +4646 2224716

Running title: Female colour morph and development time 


\section{ABSTRACT}

2

3 Although colour polymorphisms in adult organisms of many taxa are often adaptive in

4 the context of sexual selection or predation, genetic correlations between colour and other

5 phenotypic traits expressed early in ontogeny could also play an important role in

6 polymorphic systems. We studied phenotypic and genetic variation in development time

7 among female colour morphs in the polymorphic damselfly Ischnura elegans in the field

8 and by raising larvae in a common laboratory environment. In the field, the three

9 different female morphs emerged at different times. Among laboratory-raised families,

10 we found evidence of a significant correlation between maternal morph and larval

11 development time in both sexes. This suggests that the phenotypic correlation between

12 morph and emergence time in the field has a parallel in a genetic correlation between

13 maternal colour and offspring development time. Maternal colour morph frequencies

14 could thus potentially change as correlated responses to selection on larval emergence

15 dates. The similar genetic correlation in male offspring suggests that sex-limitation in this

16 system is incomplete, which may lead to an ontogenetic sexual conflict between selection

17 for early male emergence (protandry) and emergence times associated with maternal

18 morph.

19

20 Keywords: damselflies, Ischnura elegans, linkage disequilibrium, ontogenetic sexual

21 conflict, ontogeny, pleiotropy, protandry, sex-limitation 
25 Colour polymorphisms are found in many different taxa, such as birds (Galeotti et al., 26 2003; Roulin et al., 2003), amphibians (Hoffman \& Blouin, 2000), fish (Munday et al., 27 2003), reptiles (Sinervo et al., 2000), plants (Turelli et al., 2001; Schemske \& 28 Bierzychudek, 2001), and insects (Mallet \& Joron, 1999; Forsman \& Appelqvist, 1999), 29 and have become classical study systems among evolutionary biologists and ecologists. 30 Models for the maintenance of multiple morphs typically focus on negative frequency31 dependent selection resulting from intra- or interspecific biotic processes such as 32 predation (Cain \& Sheppard, 1954; Cook, 1998; Davison, 2002) or sexual selection 33 (Nielsen \& Watt, 2000). Rare morphs have an advantage in systems where predators 34 form a search image and prey more heavily on the most common morph (Allen, 1988; 35 Weale et al., 2000; Shigemiya, 2004). Rare male morphs may have an advantage under 36 sexual selection, as in the side-blotched lizard Uta stansburiana, where each of the three 37 male throat colour morphs has highest reproductive success when at low frequency 38 (Sinervo \& Lively, 1996). Sex-limited polymorphisms are usually assumed to be 39 maintained via sexual selection and male-female interactions (Svensson et al. in press).

41 Most models also implicitly assume that colour is only subject to selection in the context 42 of sexual selection or predation. It is, however, possible that there are other phenotypic 43 differences between morphs which are unrelated to colour but which are also under 44 selection, e. g. physiological traits that are expressed during earlier parts of the life-cycle. 45 Examples of such traits that are correlated with colour come from studies of colour 
46 polymorphic insects and reptiles, in which differences between morphs in traits as diverse

47 as developmental timing, fecundity, and disease resistance have been documented

48 (Fahmy \& Fahmy, 1959; Cook \& Jacobs, 1983; Wilson et al., 2001; Svensson et al.,

49 2001a; Svensson et al., 2001b; Svensson et al., 2002; True, 2003). When colour morphs

50 are genetically correlated with other traits, as in the cases cited above, selection on such

51 other traits can potentially result in a correlated response in morph frequencies.

52

53 Here, we present data from a field and laboratory study of a trimorphic damselfly, aimed 54 at investigating the links between adult colour, larval development and emergence time.

55 Female-limited polymorphisms are found in many species of damselflies (Cordero, 1992;

56 Fincke, 1994; Andrés \& Cordero Rivera, 2001; Wong et al., 2003; Sirot et al., 2003),

57 dragonflies (Corbet, 1999), and butterflies, as well as some species of birds (Bleiweiss,

58 1992; Roulin et al., 2003). Species of damselfly with female-limited colour

59 polymorphism usually have one morph that resembles a male, so-called Androchrome

60 females (Corbet, 1999). It has been suggested that Androchrome females may have a

61 selective advantage in that they can, as male mimics, avoid costly male mating

62 harassment and superfluous matings. Since differences have been found between colour

63 morphs of other insects in development time (Cook \& Jacobs, 1983; Ahnesjö \& Forsman,

64 2003), we investigated if there was evidence for a similar relationship the polymorphic

65 blue-tailed damselfly (Ischnura elegans). The results in this study suggest that female

66 colour morphs are both phenotypically and genetically correlated with larval

67 development time and emergence date. 
METHODS

70

71 Study species

72

73 Ischnura elegans is a small damselfly in which females are trimorphic and males are

74 monomorphic (Askew, 1988). The males' abdomen is black, except for the eighth

75 segment, which is blue, and they have a blue thorax with three longitudinal black stripes.

76 The Androchrome (A) morph has the same colouration and patterning as a male, and is

77 therefore considered to be a male mimic. The two other morphs are often grouped

78 together as Gynochrome morphs (Gynochrome="female-coloured"), since their

79 colouration is green (Infuscans) or brown (Infuscans-obsoleta) and potentially more

80 cryptic (Cordero et al., 1998). Though the Infuscans (I) morph has the same black

81 patterning as males and Androchromes, the Infuscans-obsoleta (IO) morph lacks two of

82 the black stripes on the thorax (the humeral stripes) and retains only the central stripe

83 (Askew, 1988). Infuscans-obsoleta females can be identified from first emergence due to

84 their unique pattern of black colouration, while Androchromes and Infuscans females are

85 both purple when immature, and impossible to distinguish until they achieve their mature 86 colouration.

87

88 The development of the female morphs of I. elegans is controlled by a single locus with

89 three alleles, as are the corresponding morphs in the sister species, I. graellsii (Cordero,

90 1990; Sánchez-Guillén et al. in press). The three alleles of the morph locus form a

91 dominance hierarchy, with the A-allele dominant to the I- and IO-alleles, the I-allele 
92 recessive to the A-allele but dominant to the IO-allele, and the IO-allele recessive to both

93 the other alleles (A>I>IO (Sánchez-Guillén et al. in press)). I. elegans has one

94 generation per year.

95

96 Emergence of females in the field

97

9814 populations outside Lund, in southern Sweden (Fjelie, Flyinge 30A1, Flyinge 30A3,

99 Genarp, Gunnesbo, Habo, Hofterups, Höje Å 14, Höje Å 6, Höje Å 7, Lomma, Lund

100 South, Vallby Mosse, and Vombs Vattenverk), were visited between the years 2000 and

101 2003. In each of these populations, damselflies were surveyed regularly over the season

102 (late May/early June to early/mid August) to determine morph frequencies. We captured

1032621 females in total, but excluded immature females from the analysis, resulting in a

104 final sample size of 2127 females. Captured females were released at a site $>1 \mathrm{~km}$ away

105 from the nearest source population, making it unlikely that females were counted twice.

106 Populations were visited in at least three out of the four years, and although in some years

107 a population may only have been visited once, most populations were usually sampled

108 repeatedly over the season (mean number of visits per season $( \pm \mathrm{SE})$ : $3.41 \pm 0.31$, mean

109 number of females caught per population each season: $39.77 \pm 4.15)$. The mean number of

110 days between separate population visits was $9.65 \pm 0.82(\mathrm{~N}=139$ unique visits in total).

111 Since damselflies have high mortality and rarely survive more than a week in the wild

112 (Cooper et al., 1996; Corbet, 1999), the capture dates of individual damselflies were

113 accordingly used as estimates of individual emergence dates. 
115 Development time in laboratory-raised families

116

117 Female I. elegans of all three morphs ( $>25$ full-sib families of each morph) were captured

118 in the field and transported to our laboratory. Eggs were obtained by placing the females

119 in small plastic cups with damp filter paper at the bottom. All females were from the

120 same population (Vombs Vattenverk) except for a few Infuscans-obsoleta females, which

121 is the rarest morph. Some Infuscans-obsoleta females were collected from other nearby

122 populations in order to provide a balanced data set. Water was added to the egg-laying

123 containers and the female removed after the eggs were laid. Once the eggs hatched, the

124 larvae were transferred to large plastic containers and fed with brine shrimp (artemia)

125 daily. Larvae were transferred to individual enclosures within the plastic containers after

126 approximately one month, in order to prevent cannibalism. They were kept under a

127 constant temperature and light regime (temperature: $17^{\circ} \mathrm{C}$, light regime: $12: 12$ ). Larvae

128 were maintained in the lab until emergence next spring, after which females were

129 released into insectaries and maintained on Drosophila until their morph status could be

130 determined.

132 Statistics

133

134 Data was analysed using mixed models (PROC MIXED, SAS (Littell et al., 1996)).

135 Development in the lab was analysed with maternal morph, sex and individual morph as

136 fixed factors, while family was considered a random factor nested within maternal

137 morph. Family was included in order to control for the non-independence of emergence 
138 date of siblings (Fry, 1992) and was nested within maternal morph since each family can

139 by definition only have one value of maternal morph (Littell et al., 1996). Maternal

140 morph and sex were included together in the analysis of all offspring (males and

141 females), whereas maternal morph and individual morph were included in the analysis of

142 female offspring. Interaction terms between fixed factors were included in both analyses.

143 We could not include all three fixed factors (maternal morph, individual morph, and sex)

144 in one analysis because males are monomorphic. Interactions between random and fixed

145 factors (family(maternal morph)*sex and family(maternal morph)*individual morph)

146 were included in the model (Newman et al., 1997) but because the interactions were non-

147 significant and did not change the results only the reduced model is presented here.

148

149 For emergence in the field, a mixed model was used with morph as a fixed effect, and

150 year and population as random effects. This is because both effects represent only a

151 subsample of all potential years and populations (Fry, 1992). All interactions were

152 initially included, but non-significant effects $(P>0.05)$ were sequentially removed from

153 the final model, starting with the highest order interactions, and only the final, reduced

154 model is presented here. In the analysis of both lab and field data post-hoc comparisons

155 of least square means were performed.

156

157 RESULTS

158

159 Emergence dates in the field

160 
161 There was a significant effect of morph on capture date in the field, as well as significant

162 effects of population and the population*year interaction (Table 1). Infuscans females

163 emerged significantly later than both Androchrome $(P<0.001)$ and Infuscans-obsoleta

164 females $(P<0.05$; Figure 1). There was no significant difference between the emergence

165 dates of Androchromes and Infuscans-obsoleta females. The morph*year and

166 morph*population interactions were not significant, which indicates that the general

167 pattern of morph emergence was the same in all populations over all years, but that the

168 actual emergence dates were earlier or later depending on the population and the year.

170 Development time of families and morphs in the laboratory

171

172 There were significant effects of sex, maternal morph and family on development time,

173 but no effect of individual morph (Table 2). Males emerged earlier than females (Figure

174 2) and the offspring of Infuscans-obsoleta females emerged significantly earlier than the

175 offspring of Androchrome $(P<0.0001)$ and Infuscans females $(P<0.01$; Figure 3$)$.

176 There was no significant difference between the offspring of Androchrome and Infuscans

177 females. The effect of maternal morph was significant both when all individuals were

178 included in the same analysis and when the sexes were analysed separately (males: $F_{2,342}$

$179=7.27, P<0.001$, females: $\left.\mathrm{F}_{2,266}=6.04, P<0.01\right)$. Restricting the analysis to only

180 Androchromes among the female offspring, we found that maternal morph also affected

181 development time in this genetically more homogenous group $\left(\mathrm{F}_{2,65}=5.29, P<0.01\right)$,

182 with a similar ordering between the family groups of the different maternal families 
183 (Infuscans-obsoleta: $285.02 \pm 4.27$; Infuscans: $298.48 \pm 4.28$; Androchrome: $302.18 \pm$

184 3.20).

185

186 DISCUSSION

187

188 Differences between morphs

189

190 Field and laboratory results in this study are concordant, revealing similar patterns of

191 development time and emergence (Figs. 1 and 3). The families of the different morphs

192 emerged at different times in the laboratory, with Infuscans-obsoleta families emerging

193 first and the families of the other two morphs later. This difference arose because larvae

194 from Infuscans-obsoleta females grow faster (J. Abbott and E. I. Svensson, unpublished

195 data) and consequently emerged earlier (Fig. 3), though at the same size as the offspring

196 of the other morphs (J. Abbott and E. I. Svensson, unpublished data). Infuscans-obsoleta

197 families always emerged the earliest, and there were consistent differences in emergence

198 times between Infuscans and Infuscans-obsoleta morphs in both the lab and the field

199 (Figs. 1 and 3). Androchrome females emerged early in the field, but offspring of

200 Androchrome females emerged late in the lab. The reason for this discrepancy is

201 unknown, but could be the result of increased sensitivity to lab conditions in

202 Androchromes (e. g. higher temperatures in the laboratory compared to natural ponds).

203 The female morphs of I. elegans and other related polymorphic species have typically

204 been considered to be pure colour morphs (Van Gossum et al., 1999; Sirot \& Brockmann,

205 2001; Andrés et al., 2002), with the morphs being identical in most respects apart from 
206 colour and patterning. These new findings of differences between morphs in both

207 development and emergence time, as well as fecundity differences (Svensson et al. in

208 press) and differences in size, shape, and growth rates (J. Abbott \& E. I. Svensson, 209 unpublished data) provide the first evidence that other traits are phenotypically or 210 genetically correlated with these colour differences.

212 The significant effect of maternal colour morph on offspring development time in both

213 sexes (Table 2) is likely to reflect a genetic correlation between the maternal and

214 offspring traits. As a caveat, we note that we cannot entirely exclude the possibility that

215 this relationship could partly be influenced by early environmental effects or non-genetic

216 maternal effects (Lynch \& Walsh, 1998), e. g. different allocation of resources to the eggs

217 provided by the three different colour morphs. Although it has previously been suggested

218 that there could be differences between colour morphs at the larval stage in I. elegans

219 (Cordero et al., 1998), investigations have been hampered by the fact that morphs are not

220 detectable at this stage in the life-cycle. In addition, sex-limited expression of colour in

221 this system makes it impossible to assign males to the different morphs. Our study, which

222 uses an experimental approach similar to another recent study on a polymorphic insect

223 (Ahnesjö \& Forsman, 2003), was partly inspired by previous workers who have tested

224 indicator models in sexual selection by correlating paternal colouration traits with various

225 measures of offspring condition or performance (Sheldon et al., 1997; Sheldon et al.,

226 2003). The advantage of using maternal values in our study is that we could include all

227 individuals in the analysis of the laboratory data, including males, larvae, and immature 
228 females, which do not express the colour patterns visible only among the adult female

229 morphs.

230

231 Mechanistic basis of the correlation between morph and development time

233 The genetic correlation between traits (maternal morph and larval development time)

234 seen here could either be caused by pleiotropic effects of single loci or linkage

235 disequilibrium between loci (Lande, 1980; Lande, 1984). Though a direct pleiotropic

236 effect of the morph locus is a possibility, we do not know at present which physiological

237 pathways connect adult colour morph and larval development rate. However, differences

238 between melanic and non-melanic morphs have been found in many insect species (True,

239 2003), probably resulting from pleiotropic effects of melanin (Wittkopp et al., 2003).

241 The lack of any detectable effect of an individual's own morph might arise from small

242 sample sizes and lack of statistical power, since not all females survived until their morph

243 could be determined (which usually requires approximately 5 days (Cooper et al., 1996)).

244 However, our results are also consistent with linkage disequilibrium caused by

245 correlational selection in the larval stage (Brodie, 1992). A selective association built up

246 in the field between emergence time and morph would be broken up through

247 recombination in the laboratory where selection is presumably absent. The result of this

248 would be an effect of morph in the field and of maternal morph on laboratory-raised

249 females, but no effect of a laboratory-raised female's own morph. 
251 Protandry and ontogenetic sexual conflict

252

253 Incomplete sex-limitation raises the prospects of an ontogenetic sexual conflict between

254 male and female development times (Chippindale et al., 2001; Rice \& Chippindale,

255 2001). Males emerged earlier than females in the laboratory (Fig. 2), a process known as

256 protandry that is likely to be adaptive in I. elegans, because its advantage in male-male

257 scramble competition for females (Andersson, 1994). Males and females may have thus

258 have different optimal emergence times, but could be prevented from reaching their

259 phenotypic optima because of a correlated response to selection in the other sex (Rice \&

260 Chippindale, 2001). We are currently investigating whether incomplete sex-limitation is

261 restricted to development time, or whether the other differences between female morphs

262 are also partly or completely expressed in males.

263

264 Differences between populations

265

266 In our laboratory study, we found differences in emergence time between families that

267 could not be attributed to the effects of sex or maternal morph (Table 2). The larvae in the

268 laboratory were kept under identical constant conditions, and variation in development

269 time therefore seems to have a genetic component, which is potentially important in

270 determining individual fitness in the field. Selection for different emergence time may

271 fluctuate according to weather conditions between years, with different genotypes

272 (families or morphs) being favoured in different years. The absence of morph*population

273 or morph*year interactions in our analysis of field-caught females (Table 1) suggest that 
274 the morph-specific pattern of emergence is fairly consistent across all populations and

275 years, although the average emergence times differ between populations and years.

276

277 The significant population effect on emergence shows that some populations are

278 consistently earlier or later. This could be due to environmental effects on water

279 temperature and perhaps genetic differences between populations (Table 1). Morph

280 frequencies are also known to vary between populations and within populations over

281 different generations (E. I. Svensson \& J. Abbott, unpublished data), which is of

282 particular interest in relation to the spatial and temporal differences in emergence time

283 demonstrated in this study. Since infuscans-obsoleta and androchromes females emerged

284 earlier (Fig. 1), variable weather patterns over the summer could influence morph

285 frequencies over subsequent generations.

286

287 Relevance to maintenance of the polymorphism

288

289 Because female morph is correlated with development time, selection on the colour locus

290 may not be restricted to the mating interactions among adults, the focus of most previous

291 studies. Selection on other traits, such as date of emergence, could potentially also affect

292 morph frequency dynamics. Recently, Reinhold (Reinhold, 2000) presented a model

293 which suggests that fluctuating selection can maintain sex-limited polymorphisms

294 because the sex that does not express the polymorphic trait acts as a shield protecting

295 temporarily disfavoured alleles from selection. There is the potential for substantial

296 survival selection on emergence date, and since development time differs between 
297 morphs in the field (Fig. 1; Table 1), has a clear genetic component, and appears to be 298 genetically correlated with colour (Table 2), such selection could result in a correlated 299 response in morph frequencies across generations.

300

301 Conclusions

302

303 Results in this study suggest that there is a genetic correlation between morph and 304 development time, and by extension, with emergence date in the field. This presents us 305 with several interesting avenues of further research, such as differential sensitivity of the 306 morphs to abiotic or biotic conditions, the relative importance of maternal effects in this 307 system, pleiotropy versus linkage disequilibrium as the cause of the genetic correlation, 308 incomplete sex-limitation of other traits associated with female morph, and the possibility 309 of different optimal emergence times of males and females. Although there is other 310 evidence of frequency-dependent selection at the adult stage in I. elegans (Svensson et al.

311 in press), the contribution of correlated responses to selection on larval traits to the 312 maintenance of the polymorphism will require continued investigation..

\section{ACKNOWLEDGEMENTS}

315

316 We are grateful to Stefan Baumgartner for supplying Drosophila, and to Anna

317 Antonsson, Audrey Coreau, Thomas Gosden, Hedvig Hogfors, Beatriz Jañez, Jan

318 Jönsson, Anna Persson and Patrik Stenroth for assistance in the laboratory and in the

319 field. We also wish to thank Stefan Andersson and Roger Härdling for comments on the 
320 first draft of this manuscript. This study is part of a long-term study of the ecological

321 genetics and evolutionary biology of I. elegans. Financial support has been provided by

322 the Swedish Research Council and Oscar \& Lilli Lamms Stiftelse (to E. S.). 


\section{REFERENCES}

Ahnesjö, J. and Forsman, A. 2003. Correlated evolution of colour pattern and body size in polymorphic pygmy grasshoppers, Tetrix undulata. J. Evol. Biol. 16: 1308-1318.

Allen, J. A. 1988. Frequency-dependent selection by predators. Philos. Trans. R. Soc. Lond. B Biol. Sci. 319: 485-503.

Andersson, M. 1994. Sexual selection. Princeton University Press, Princeton.

Andrés, J. A. and Cordero Rivera, A. 2001. Survival rates in a natural population of the damselfly Ceriagrion tenellum: effects of sex and female phenotype. Ecol. Entomol. 26: 341-346.

Andrés, J. A., Sánchez-Guillén, R. A., and Cordero Rivera, A. 2002. Evolution of female colour polymorphism in damselflies: testing the hypotheses. Anim. Behav. 63: 677-685.

Askew, R. R. 1988. The dragonflies of Europe. Harley Books, Colchester, Essex.

Bleiweiss, R. 1992. Reversed plumage ontogeny in a female hummingbird: implications for the evolution of iridescent colours and sexual dichromatism. Biol. J. Linn. Soc. 47: 183-195.

Brodie, E. D., III. 1992. Correlational selection for colour pattern and antipredator behavior in the garter snake Thamnophis ordinoides. Evolution 46: 1284-1298.

Cain, A. J. and Sheppard, P. M. 1954. Natural selection in Cepaea. Genetics 39: 89-116.

Chippindale, A. K., Gibson, J. R., and Rice, W. R. 2001. Negative genetic correlation for adult fitness between sexes reveals ontogenetic conflict in Drosophila. Proc. Nat. Acad. Sci. USA 98: 1671-1675.

Cook, L. M. 1998. A two-stage model for Cepaea polymorphism. Philos. Trans. R. Soc. Lond. B Biol. Sci. 353: 1577-1593.

Cook, L. M. and Jacobs, T. M. G. M. 1983. Frequency and selection in the industrial melanic moth Odonoptera bidentata. Heredity 51: 487-494. 
Cooper, G., Holland, P. W. H., and Miller, P. L. 1996. Captive breeding of Ischnura elegans (Vander Linden): observations on longevity, copulation and oviposition (Zygoptera: Coenagrionidae). Odonatologica 25: 261-273.

Corbet, P. S. 1999. Dragonflies: behaviour and ecology of Odonata. Harley Books, Colchester, Essex.

Cordero, A. 1990. The inheritance of female polymorphism in the damselfly Ischnura graellsii (Rambur) (Odonata: Coenagrionidae). Heredity 64: 341-346.

Cordero, A. 1992. Density-dependent mating success and colour polymorphism in females of the damselfly Ischnura graellsii (Odonata: Coenagrionidae). J. Anim. Ecol. 61: 769-780.

Cordero, A., Santolamazza Carbone, S., and Utzeri, C. 1998. Mating opportunities and mating costs are reduced in androchrome female damselflies, Ischnura elegans (Odonata). Anim. Behav. 55: 185-197.

Davison, A. 2002. Land snails as a model to understand the role of history and selection in the origins of biodiversity. Popul. Ecol. 44: 129-136.

Fahmy, O. G. and Fahmy, M. 1959. New mutants report. Drosophila Information Services 33: 82-94.

Fincke, O. M. 1994. Female colour polymorphism in damselflies: failure to reject the null hypothesis. Anim. Behav. 47: 1249-1266.

Forsman, A. and Appelqvist, S. 1999. Experimental manipulation reveals differential effects of colour pattern on survival in male and female pygmy grasshoppers. J. Evol. Biol. 12: 391-401.

Fry, J. D. 1992. The mixed-model analysis of variance applied to quantitative genetics: biological meaning of the parameters. Evolution 46: 540-550.

Galeotti, P., Rubolini, D., Dunn, P. O., and Fasola, M. 2003. Colour polymorphism in birds: causes and functions. J. Evol. Biol. 16: 635-646. 
Hoffman, E. A. and Blouin, M. S. 2000. A review of colour and pattern polymorphisms in anurans. Biol. J. Linn. Soc. 70: 633-665.

Lande, R. 1980. The genetic covariance between characters maintained by pleiotropic mutations. Genetics 94: 203-215.

Lande, R. 1984. The genetic correlation between characters maintained by selection, linkage and inbreeding. Genet. Res. Camb. 44: 309-320.

Littell, R. C., Milliken, G. A., Stroup, W. W., and Wolfinger, R. D. 1996. SAS system for mixed models. SAS Institute Inc., Cary, NC.

Lynch, M. and Walsh, B. 1998. Genetics and analysis of quantitative traits. Sinauer Associates, Inc., Sunderland, MA.

Mallet, J. and Joron, M. 1999. Evolution of diversity in warning color and mimicry: polymorphisms, shifting balance, and speciation. Annu. Rev. Ecol. Syst. 30: 201-233.

Munday, P. L., Eyre, P. J., and Jones, G. P. 2003. Ecological mechanisms for coexistence of colour polymorphism in a coral-reef fish: an experimental evaluation. Oecologia 137: 519-526.

Nielsen, M. G. and Watt, W. B. 2000. Interference competition and sexual selection promote polymorphism in Colias (Lepidoptera, Pieridae). Funct. Ecol. 14: 718-730.

Reinhold, K. 2000. Maintenance of a genetic polymorphism by fluctuating selection on sex-limited traits. J. Evol. Biol. 13: 1009-1014.

Rice, W. R. and Chippindale, A. K. 2001. Intersexual ontogenetic conflict. J. Evol. Biol. 14: 685-693.

Roulin, A., Ducret, B., Ravussin, P.-A., and Altwegg, R. 2003. Female colour polymorphism covaries with reproductive strategies in the tawny owl Strix aluco. Journal of Avian Biology 34: 393-401.

Sánchez-Guillén, R. A., Van Gossum, H., and Cordero Rivera, A. 2005. Hybridization and the inheritance of female colour polymorphism in two Ischnurid damselflies (Odonata: Coenagrionidae). Biol.J.Linn.Soc. In press. 
Schemske, D. W. and Bierzychudek, P. 2001. Evolution of flower colour in the desert annual Linanthus parryae: Wright revisited. Evolution 55: 1269-1282.

Sheldon, B. C., Arponen, H., Laurila, A., Crochet, P.-A., and Merilä, J. 2003. Sire coloration influences offspring survival under predation risk in the moorfrog. J. Evol. Biol. 16: 1288-1295.

Sheldon, B. C., Merilä, J., Qvarnström, A., Gustafsson, L., and Ellegren, H. 1997. Paternal genetic contribution to offspring condition predicted by size of male secondary sexual character. Proc. R. Soc. Lond. B Biol. Sci. 264: 297-302.

Shigemiya, Y. 2004. Reversible frequency-dependent predation of a puffer, Takifugu niphobles (Pisces: Tetraodontidae), related to spatial distribution of colour-polymorphic prey. Biol. J. Linn. Soc. 81: 197-202.

Sinervo, B. and Lively, C. M. 1996. The rock-paper-scissors game and the evolution of alternative male strategies. Nature 380: 240-243.

Sinervo, B., Svensson, E., and Comendant, T. 2000. Density cycles and an offspring quantity and quality game driven by natural selection. Nature 406: 985-988.

Sirot, L. K. and Brockmann, H. J. 2001. Costs of sexual interactions to females in Rambur's forktail damselfly, Ischnura ramburi (Zygoptera: Coenagrionidae). Anim. Behav. 61: 415-424.

Sirot, L. K., Brockmann, H. J., Marinis, C., and Muschett, G. 2003. Maintenance of a female-limited polymorphism in Ischnura ramburi (Zygoptera: Coenagrionidae). Anim. Behav. 66: 763-775.

Svensson, E., Sinervo, B., and Comendant, T. 2001a. Condition, genotype-byenvironment interaction, and correlational selection in lizard life-history morphs. Evolution 55: 2053-2069.

Svensson, E., Sinervo, B., and Comendant, T. 2001b. Density dependent competition and selection on immune function in genetic lizard morphs. Proc. Nat. Acad. Sci. USA 98: 12561-12565. 
Svensson, E., Sinervo, B., and Comendant, T. 2002. Mechanistic and experimental analysis of condition and reproduction in a polymorphic lizard. J. Evol. Biol. 15: 10341047.

Svensson, E. I., Abbott, J., and Härdling, R. 2005. Female polymorphism, frequencydependence and rapid evolutionary dynamics in natural populations. Am.Nat. In press.

True, J. R. 2003. Insect melanism: the molecules matter. Trends Ecol. Evol. 18: 640-647.

Turelli, M., Schemske, D. W., and Bierzychudek, P. 2001. Stable two-allele polymorphisms maintained by fluctuating fitnesses and seed banks: protecting the blues in Linanthus parryae. Evolution 55: 1283-1298.

Van Gossum, H., Stoks, R., Matthysen, E., Valck, F., and De Bruyn, L. 1999. Male choice for female colour morphs in Ischnura elegans (Odonata, Coenagrionidae): testing the hypotheses. Anim. Behav. 57: 1229-1232.

Weale, M. E., Whitwell, D., Raison, H. E., Raymond, D. L., and Allen, J. A. 2000. The influence of density on frequency-dependent food selection: a comparison of four experiments with wild birds. Oecologia 124: 391-395.

Wilson, K., Cotter, S. C., Reeson, A. F., and Pell, J. K. 2001. Melanism and disease resistance in insects. Ecology Letters 4: 637-649.

Wittkopp, P. J., Carroll, S. B., and Kopp, A. 2003. Evolution in black and white: genetic control of pigment patterns in Drosophila. Trends Genet 19: 495-504.

Wong, A., Smith, M. L., and Forbes, M. R. 2003. Differentiation between subpopulations of a polychromatic damselfly with respect to morph frequencies, but not neutral genetic markers. Mol. Ecol. 12: 3505-3513. 
Table 1: Table of effects of morph, population, and year on capture date of field-caught females $(\mathrm{N}=2127)$. Data was analysed using a mixed model with population and year as random effects, and morph as a fixed effect. For fixed effects (morph) the test statistic is F, for random effects (population, year, and population*year) it is Z. The initial model included all interactions, and non-significant interaction effects were sequentially removed (starting with the highest-order interactions) to give the final model presented here.

$\begin{array}{lllll}\text { Effect } & \text { df } & \text { F } & \mathrm{Z} & P \text {-value }\end{array}$

\begin{tabular}{|c|c|c|c|}
\hline Morph & 2 & & 0.0027 \\
\hline Population & 13 & 1.82 & 0.0346 \\
\hline Population*year & 39 & 3.85 & $<0.0001$ \\
\hline
\end{tabular}


Table 2: Table of effects of maternal morph, sex, individual morph, and family on development time in the laboratory. Maternal morph and sex were included in the first analysis (all offspring), maternal morph and individual morph in the second (females only) and maternal morph in the third (males only). All three analyses were mixed models with family as a random effect. For fixed effects (maternal morph, sex, individual morph) the test statistic is F, for random effects (family) it is $\mathrm{Z}$.

$\begin{array}{llllll}\text { Effect } & \text { df } & \text { F } & Z & P \text {-value }\end{array}$

All offspring $(\mathrm{N}=608)$

Maternal morph

2

7.97

0.0007

Sex

1

12.77

0.0004

Maternal morph*sex

2

0.84

0.4342

Family(maternal morph)

77

4.33

$<0.0001$

Female offspring only $(\mathrm{N}=237)$

Maternal morph

2

4.28

0.0175

Individual morph

2

0.43

0.6481

Maternal morph*individual morph 4

0.40

0.8064

Family(maternal morph)

74

3.45

0.0003

Male offspring only $(\mathrm{N}=342)$

Maternal morph

2

7.27

0.0013

Family(maternal morph)

77

2.60

0.0047 
Figure 1: Capture date (julian day $\pm \mathrm{SE}$ ) in the field of females of the three morphs.

Infuscans females were captured significantly later than either of the two other morphs $(P<0.05)$

Figure 2: Development time (days $\pm \mathrm{SE}$ ) in the laboratory in relation to sex. Males had a significantly shorter development time than females $(P<0.001)$.

Figure 3: Development time (days $\pm \mathrm{SE}$ ) in the lab for offspring of the three female morphs. Offspring of infuscans-obsoleta females had a significantly shorter development time than the offspring of the other two morphs $(P<0.01)$. 


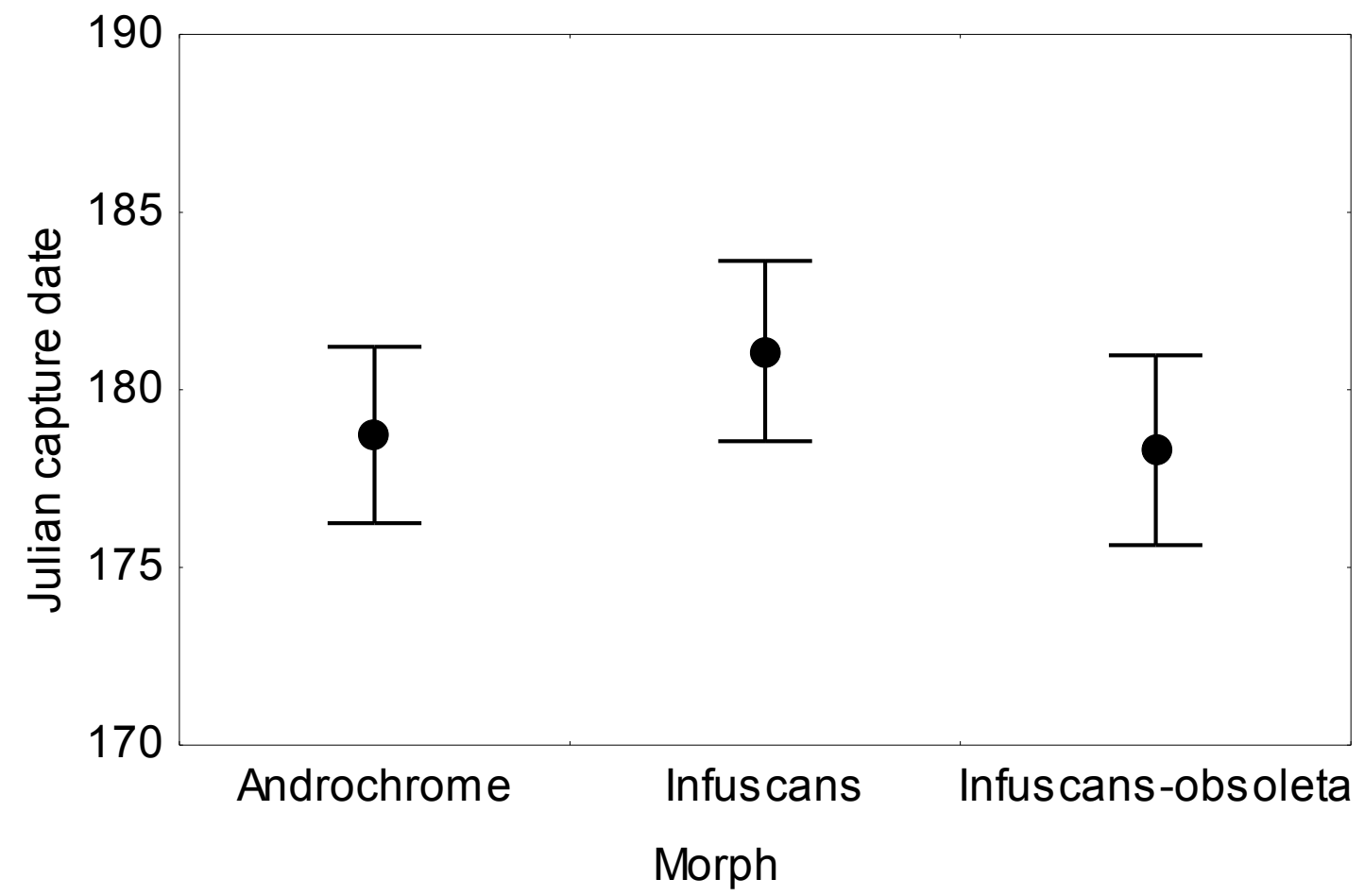

Figure 1 


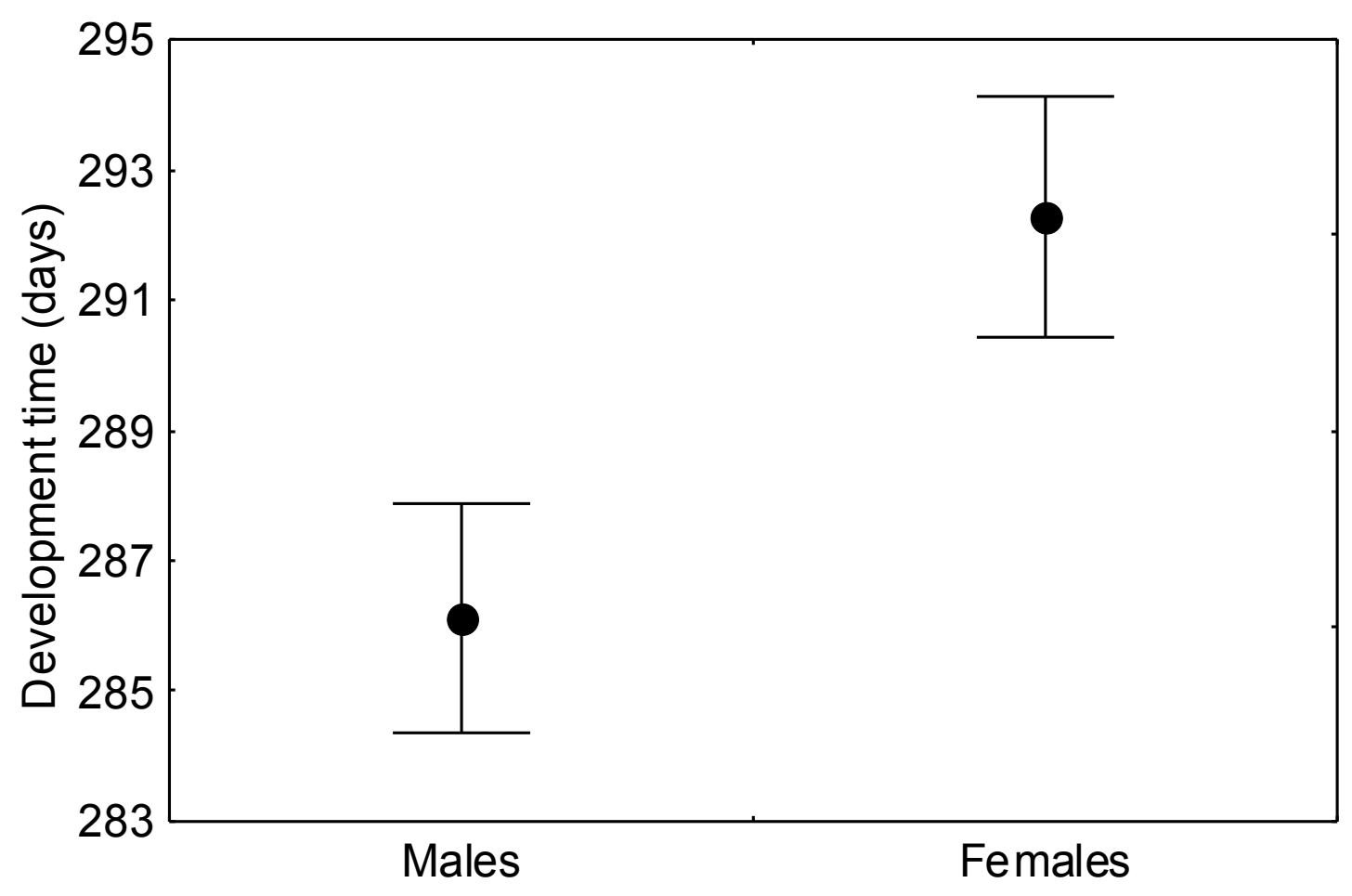

Figure 2 


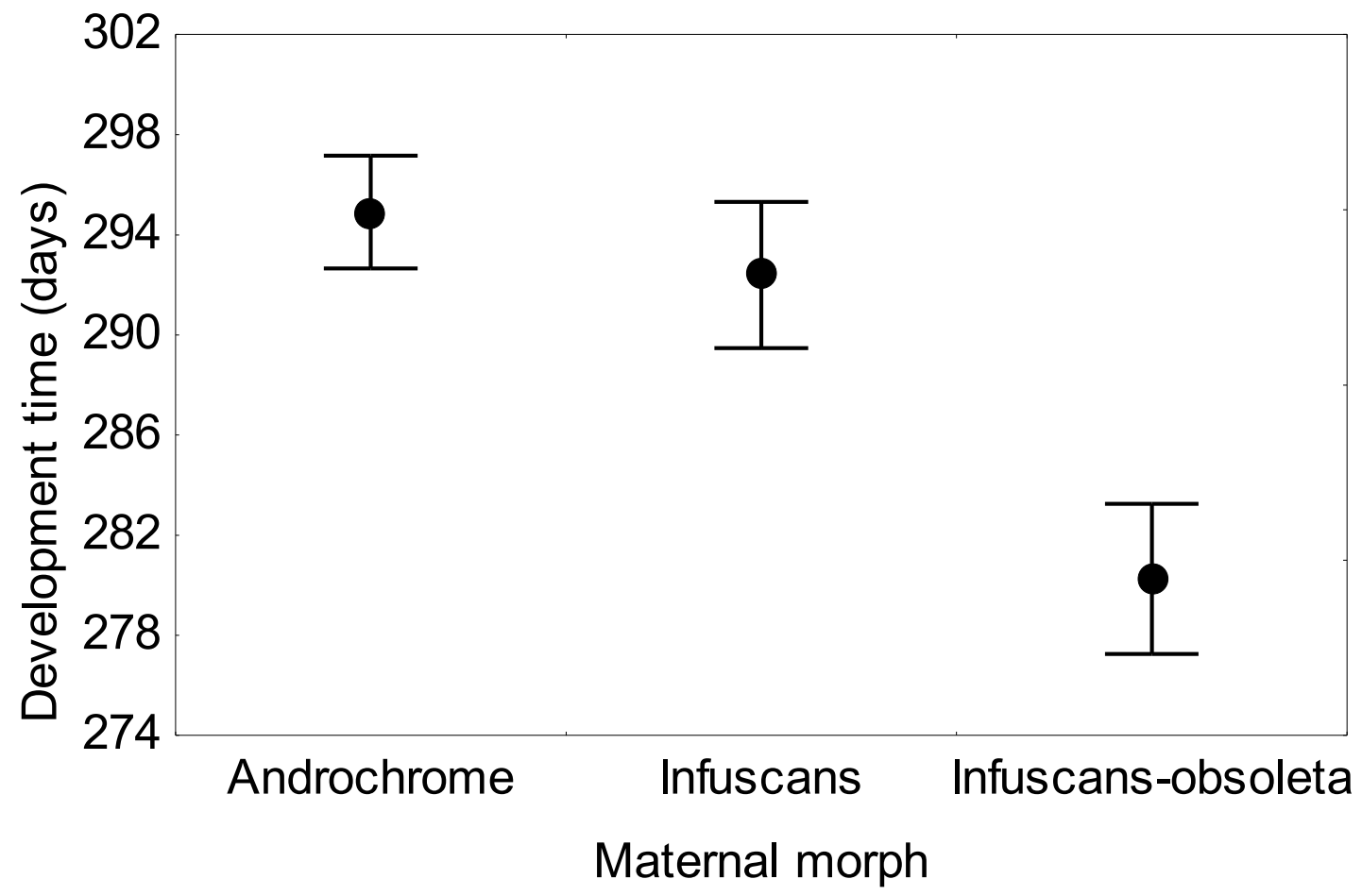

Figure 3 